\title{
Growth of Cyanobacterium aponinum influenced by increasing salt concentrations and temperature
}

\author{
Dominik Winckelmann • Franziska Bleeke • \\ Peter Bergmann • Gerd Klöck
}

Received: 16 January 2014/ Accepted: 29 April 2014/Published online: 18 May 2014

(C) The Author(s) 2014. This article is published with open access at Springerlink.com

\begin{abstract}
The increasing requirement of food neutral biofuels demands the detection of alternative sources. The use of non-arable land and waste water streams is widely discussed in this regard. A Cyanobacterium was isolated on the area of a possible algae production side near a water treatment plant in the arid desert region al-Wusta. It was identified as Cyanobacterium aponinum PB1 and is a possible lipid source. To determine its suitability of a production process using this organism, a set of laboratory experiments were performed. Its growth behavior was examined in regard to high temperatures and increasing $\mathrm{NaCl}$ concentrations. A productivity of $0.1 \mathrm{~g} \mathrm{~L}^{-1}$ per day was measured at an alga density below $0.75 \mathrm{~g} \mathrm{~L}^{-1}$. $C$. aponinum $\mathrm{PB} 1$ showed no sign of altered growth behavior in media containing $70 \mathrm{~g} \mathrm{~L}^{-1} \mathrm{NaCl}$ or less. Detection of a negative effect of $\mathrm{NaCl}$ on the growth using PulseAmplitude-Modulation chlorophyll fluorescence analysis was not more sensitive than optical density measurement.
\end{abstract}

Keywords PAM - Bio fuel - Cyanobacterium aponinum . Evaporation · Open pond · Arid desert

\section{Introduction}

Microalgae and cyanobacteria were considered to be a good choice as lipid source for bio diesel production, for

D. Winckelmann · F. Bleeke

School of Engineering and Science, Jacobs-University Bremen, Campus Ring 1, 28759 Bremen, Germany

D. Winckelmann · F. Bleeke · P. Bergmann · G. Klöck $(\bowtie)$ University of Applied Sciences Bremen, Am Neustadtswall 30, 28199 Bremen, Germany

e-mail: Gerd.Kloeck@hs-bremen.de
$\mathrm{CO}_{2}$ sequestration, as nutritional supplement and for numerous other applications (Chisti 2008; Grobbelaar 2012). Recent studies consider microalgae and cyanobacteria to be not able to be used as a stand-alone commercial production process, but to be a means to utilize waste streams of other processes or to be a solution for a smallscale niche products (Van Beilen 2010; Chisti 2013). During the crude oil production in the Sultanate of Oman $800,000 \mathrm{~m}^{3}$ of contaminated production water accumulates per day (Breuer and Al-Asmi 2010). Part of the water is treated in a reed bed water treatment plant. Different options for further use of the treated water are under investigation. One possible option is to establish an algae growth facility for which the possible location would be in the arid desert region al-Wusta, Oman.

The use of non-arable land in a desert region has the advantage of sustainable production without competing with possible crop production (Singh et al. 2011), while it raises some possible difficulties. The maximum light exposure, annual temperature regime, cloud coverage, availability of water and the general infrastructure are considered to be major factors influencing the production in large-scale algae cultures (Grobbelaar 2009). Furthermore a high evaporation rate and the high consumption of fresh water to keep the salinity of the growth medium under a certain threshold is an important economic factor (Guieysse et al. 2013). The use of indigenous species as production organisms, either in axenic cultures or as mixed cultures, is said to circumvent some of the difficulties associated with the location (Mutanda et al. 2011; Odlare et al. 2011).

In preparation of the establishment of an algae-production site in an arid desert, the effect of warm temperature and increasing salt content on the growth of a domestic specie and the possible productivity were determined. 
Therefore, the first step was to isolate different algae species from the water treatment plant. Thereby a strain of Cyanobacterium aponinum was found. C. aponinum is said to be able to grow in fresh and seawater media at temperatures of up to $45{ }^{\circ} \mathrm{C}$ (Moro et al. 2007) and might be used as lipid source (Karatay and Dönmez 2011).

The goal during the development of an algae growth process has to be to provide a process, which is able to deliver a stable biomass and product outcome, while being robust against outer circumstances. Grobbelaar (2000) gave an overview about the different fields and possibilities of improvement to optimize mass algal culture. He stated that process control should be improved to allow exploitation of physiological properties of the species to be grown. It was emphasized that carbon fixation and metabolism, and maximum photosynthetic rate are important to determine the overall efficiency of the photo capture and net carbon fixation, and possible damage to the photosystem reaction centers.

PAM chlorophyll fluorescence analysis were performed in laboratory studies to estimate $\mathrm{CO}_{2}$ fixation, light acclimation states (Behrenfeld et al. 2004; Campbell et al. 1998), and the influence of salt stress on photosynthesis ( $\mathrm{Lu}$ and Vonshak 1999) in cyanobacteria and green algae using the pulse modulation principle (Schreiber et al. 1986). But the large-scale cultivation of algae opens up some new, so far not existing challenges and raise the need for real time online measurement methods (Havlik et al. 2013).

Chlorophyll fluorescence analysis was performed during this study using a phyto-PAM, which was designed to distinguish between fluorescence excited by light of four different preset wavelengths (Kolbowski and Schreiber 1995) and thereby enable an estimate of the relative pigment-content associated with those wavelengths.

\section{Methods}

Culture media

With regard to future industrial sized applications a simple media containing the commercially available fertilizer WUXAL $^{\circledR}$ Universaldünger liquid plant fertilizer $(8 \% \mathrm{~N}$, $8 \% \mathrm{P}_{2} \mathrm{O}_{5}, 6 \% \mathrm{~K} 2 \mathrm{O}, 0.01 \% \mathrm{~B}, 0.004 \% \mathrm{Cu}, 0.02 \% \mathrm{Fe}$, $0.012 \% \mathrm{Mn}, 0.004 \% \mathrm{Zn}$; Wilhelm Haug GmbH \& Co. $\mathrm{KG}$, Germany) was used. The $\mathrm{NaCl}$ concentration added to the media was chosen corresponding to the salinity of the natural environment $C$. аропinum was isolated from. Wuxal liquid medium (WM) contained tap water with $0.002 \% \mathrm{w} / \mathrm{v} \mathrm{MgSO}_{4}, 1 \% \mathrm{w} / \mathrm{v} \mathrm{NaCl}$ and $0.05 \% \mathrm{v} / \mathrm{v}$ Wuxal. Wuxal was sterile filtrated and added after autoclaving.

\section{Isolation of algae}

Environmental samples were taken in a reed bed system near Nimr, Sultanate of Oman $\left(+18^{\circ} 34^{\prime} 14.98^{\prime \prime} \mathrm{N},+55^{\circ}\right.$ $49^{\prime} 5.99^{\prime \prime}$ E). Initial growth was conducted in Erlenmeyer flasks containing WM soil media (WM with $3 \% \mathrm{v} / \mathrm{v}$ soil extract (Watanabe 2005)) for 7 days at room temperature and natural light. After biomass increase was visible, the flasks were transferred into a light incubator (RUMED Licht Thermostat Typ 1301, Rubarth Apparate GmbH, Germany) and cultivated at $40^{\circ} \mathrm{C}$ and $110 \pm 2.5$ PAR $\mathrm{m}^{-2} \mathrm{~s}^{-1}$. The flasks were shaken constantly at 150 rounds per minute (orbital shaker 3005, GFL-Gesellschaft für Labortechnik mbH, Germany). Single-celled algae were isolated using the 13-streak method on WM- soil plates containing $1.5 \%(\mathrm{w} / \mathrm{v})$ Agar. The agar plates were grown in the light incubator until growth was visible. Colonies containing only one algae species were transferred to liquid media.

Identification of algae

Genomic DNA was extracted from freshly grown $C$. aponinum PB1. Cells were broken-up via beat mill and DNA was extracted using a DNA extraction kit (DNeasy Plant Mini kit, Qiagen, Germany).The 16 s rRNA gene was amplified by PCR using the primers CYA106F, and a mixture of CYA781R (a) and CYA781R (b) (Boutte et al. 2006); (GenBank: JN584264.1)) and the internal transcribed spacer between the 16S and 23S rRNA genes (ITS) was amplified using the primer pair ULR and CSIF (without the G-C clamp (Janse et al. 2003); GenBank: KF982001). The PCR product was purified using the QIAquick PCR Purification Kit (Qiagen, Germany). Sequencing was performed using the Sanger sequencing technique by GATC Biotech AG (Germany).

\section{Characterization of algae}

The optical density was measured at $700 \mathrm{~nm}$ (OD700) using a Thermo Spectronic Genesys 20 Model 4001/4 (Thermo Electron Corporation, USA). For the determination of bio dry weight, part of a culture was washed and filtered. The filter was dried at $105{ }^{\circ} \mathrm{C}$ until the weight was constant.

Fluorescence analysis was performed using a phytoPAM with phyto-EDF (Walz, Germany). The samples were transferred in a $1.5 \mathrm{ml}$ cup and the perspex-rod sensor tip was $0.2 \mathrm{~mm}$ immersed into the algae suspension. Everything was covered and the fluorescence was measured (Settings: gain was adjusted to $\mathrm{F} 645 \mathrm{~nm}$ values above 200 and below 400, measuring light intensity 0 , saturation light 
intensity 10, saturation pulse length $400 \mathrm{~ms}$; For introduction, see (Schreiber et al. 1995)).

Each chlorophyll fluorescence measurement performed delivered four light-adapted steady state fluorescence values $\left(F^{\prime} x\right)$ and four maximum fluorescence values $\left(F^{\prime} m x\right)$, which were assigned to one of the four different used excitation wave length ( $x=470,520,645$ or $665 \mathrm{~nm}$ ). The effective quantum efficiency of charge separation at photosystem II (yield) in actinic light was calculated according to Genty et al. (Kaplan et al. 1989) for each wavelength used (yield $x$ ).

Yield $=\frac{F^{\prime} m-\mathrm{F}}{F^{\prime} m}$

To determine a shift in light utilization the ratio of steady-state fluorescence was calculated. The maximum signal of $F^{\prime} x$ was set as 1 , the lower values were normalized against it resulting in three values called rel.Fx.

Microalgae cultivation

Stock cultures of $C$. aponinum PB1 were grown in Erlenmeyer flasks at $24 \pm 2{ }^{\circ} \mathrm{C}$ and illuminated with white fluorescent light $\left(60 \pm 2.5 \mathrm{PAR} \mathrm{m}^{-2} \mathrm{~s}^{-1}\right.$, measured using Meteon Irradiance meter with a PAR Lite sensor (Kipp and Zonen, Netherlands)). Temperature was measured using a Hobo ${ }^{\circledR}$ Pendant temp \#UA-001-64 (Onset Computer Corporation, USA).

The growth experiment was performed at $38 \pm 2{ }^{\circ} \mathrm{C}$. All cultures were illuminated with white fluorescent light $\left(110 \pm 2.5 \mathrm{PAR} \mathrm{m}^{-2} \mathrm{~s}^{-1}\right.$ for $14 \mathrm{~h}$ per day, in $49 \mathrm{~cm}$ high glass tubes with an inner diameter of $49 \mathrm{~mm}$ and a total liquid volume of $750 \mathrm{ml}$, and aerated with fresh air at a rate of $100 \mathrm{l} / \mathrm{h}$. Initial inoculum was $1 \times 10^{6}$ cells per ml. The OD700, cell concentration (determined using a Zeiss Axiostar Plus light microscope (Carl Zeiss, Germany) and a Thoma Neu chamber with a depth of $0.1 \mathrm{~mm}$ (Paul Marienfeld GmbH \& Co. KG, Germany), pH (using a wtw pH 315i (WTW WissenschaftlichTechnische Werkstätten GmbH, Germany)) with an InLab Micro pH electrode (Mettler Toledo GmbH, Germany)), and chlorophyll fluorescence were determined twice a week before nine in the morning. Evaporated water was replaced with tap water or a $\mathrm{NaCl}$ solution $(10 \% \mathrm{w} / \mathrm{v} \mathrm{NaCl}$ in tap water) and salinity was measured twice a week (using a conductivity meter LF 340 with a TetraCon ${ }^{\circledR} 325$ (WTW WissenschaftlichTechnische Werkstätten GmbH, Germany).

\section{Results}

Characterization of C. aponinum PB1

The sequence for the 16S rRNA gene covered 412 bases and the sequence gained for the ITS region covered 441

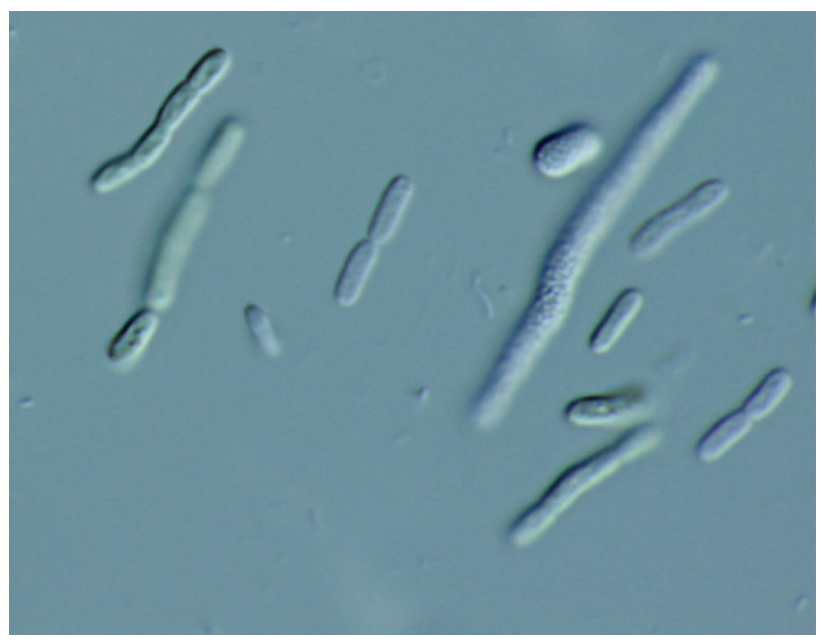

Fig. 1 Picture of C. aponinum PB1 (Culture was grown for 14 days in WM), Picture was made by Gerhard Kauer with light microscope and 630-fold magnification

bases. After BLAST (Altschup et al. 1990) analysis a similarity of $99 \%$ with an $E$ value of 0.0 to $C$. aponinum PCC 10605 (GenBank: CP003947.1), respectively, $100 \%$ and $E$ value of 0.0 for the 16S rRNA gene alone (NR_102443.1), and a similarity of $98 \%$ with an $E$ value of 0.0 to $C$. aponinum ETS-03 (GenBank: AM238427.1) were found.

Cyanobacterium aponinum PB1 grow in peanut-like or cylindrical shape with a length of 3-4 $\mu \mathrm{m}$ and a diameter of 2-3 $\mu \mathrm{m}$. They appear solitary or during cell division as pairs. Grown under nutrient-limited conditions they show elongated cell shapes (Fig. 1). They appear blue-green in color.

Cyanobacterium aponinum $\mathrm{PB} 1$ is able to grow at $45{ }^{\circ} \mathrm{C}$ and $110 \mathrm{PAR} \mathrm{m}^{-2} \mathrm{~s}^{-1}$ (14 h light and $10 \mathrm{~h}$ dark) in WM with $10 \mathrm{~g} \mathrm{~L}^{-1} \mathrm{NaCl}$. Grown using the same experimental set-up at $28{ }^{\circ} \mathrm{C}$ and 180 PAR m ${ }^{-2} \mathrm{~s}^{-1}(14 \mathrm{~h}$ light and $10 \mathrm{~h}$ dark) exponential growth was achieved over a period of 14 days with a growth rate $\mu$ per day of 0.3 (SD 0.006) and a maximum light-adapted yield $645 \mathrm{~nm}$ of 0.45 (data not shown). The constant bio dry weight of washed cultures with an OD700 of 1 was $0.51 \mathrm{~g} \mathrm{~L}^{-1}$ (SD 0.0075). Cultures grown at RT showed no DNA fragmentation (Nedelcu 2006) after incubation at $42{ }^{\circ} \mathrm{C}$ in the dark (Fig. 2).

Growth in WM with increasing $\mathrm{NaCl}$ content

Cyanobacterium aponinum PB1 was grown in media with increasing $\mathrm{NaCl}$ concentrations (referred to as treated culture), namely 10, 13, 20, 26, 35, 58, 70, 92, and $140 \mathrm{~g} \mathrm{~L}^{-1}$, and stable NaCL concentration $\left(10 \mathrm{~g} \mathrm{~L}^{-1}\right.$, referred to as control culture). Growth was exponential for both cultures till day 6, when the $\mathrm{NaCl}$ content was increased to $20 \mathrm{~g} \mathrm{~L}^{-1}$, and their growth rate $\mu$ per day was comparable 
Fig. 2 No indication of $C$. aponinum genomic DNA fragmentation after $2 \mathrm{~h}$ incubation at $42^{\circ} \mathrm{C}$ (right lane) compared to $2 \mathrm{~h}$ incubation at room temperature (RT, left lane). DNA fragmentation was performed like described in Nedelcu 2006

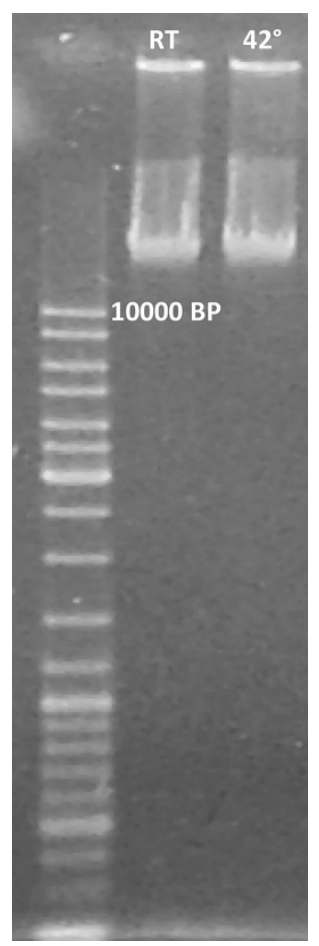

with 0.35 for the treated culture and 0.33 for the control. Afterwards, the growth was linear with an increase of $1.3 \times 10^{6}$ cells per $\mathrm{ml}$ per day for the treated and $0.9 \times 10^{6}$ cells per $\mathrm{ml}$ per day for the control culture till day 16 , after which the $\mathrm{NaCl}$ concentration was increased to $92 \mathrm{~g} \mathrm{~L}^{-1}$. The cell density of treated culture decreased from $3 \times 10^{7}$ to $1.8 \times 10^{7}$ cells $/ \mathrm{ml}$ during the growth in WM containing $92 \mathrm{~g} \mathrm{~L}^{-1} \mathrm{NaCl}$ and even further to $1.5 \times 10^{7}$ cells $/ \mathrm{ml}$ after the $\mathrm{NaCl}$ content was increased to $140 \mathrm{~g} \mathrm{~L}^{-1}$. The cell content in the control culture stayed stable at $3 \times 10^{7}$ cells per $\mathrm{ml}$ over the whole time (Fig. 3). The optical density showed a similar course like the cell count (Fig. 4). The coloration became less green and paler after the $\mathrm{NaCl}$ content was $92 \mathrm{~g} \mathrm{~L}^{-1}$ or higher. The $\mathrm{pH}$ rose in the first 2 days from 7.8 to 9 on day 6 , when the NACL content was increased to $20 \mathrm{~g} \mathrm{~L}^{-1}$, but decreased till day 16 , after which the $\mathrm{NaCl}$ concentration was increased to $92 \mathrm{~g} \mathrm{~L}^{-1}$, to 5.8 for the treated culture and 5.5 for the control. Over the whole course the $\mathrm{pH}$ of the treated culture was slightly higher. This changed after the $\mathrm{NaCl}$ content was increased to $92 \mathrm{~g} \mathrm{~L}^{-1}$ when the $\mathrm{pH}$ of both cultures was at 5.6. The $\mathrm{pH}$ of the treated culture stayed stable during growth in $140 \mathrm{~g} \mathrm{~L}^{-1} \mathrm{Nacl}$ while the $\mathrm{pH}$ of the control culture slightly increased (Fig. 4).

The yield of the treated culture increased from 0.12 in media containing $10 \mathrm{~g} \mathrm{~L}^{-1} \mathrm{NaCl}$ to 0.4 in media containing $58 \mathrm{~g} \mathrm{~L}^{-1} \mathrm{NaCl}$ and decreased stepwise to 0.12 when the culture was grown in media containing $140 \mathrm{~g} \mathrm{~L}^{-1}$ $\mathrm{NaCl}$. The yield of the control culture increased from 0.22 to 0.31 and stabilized at 0.28 (Fig. 5).

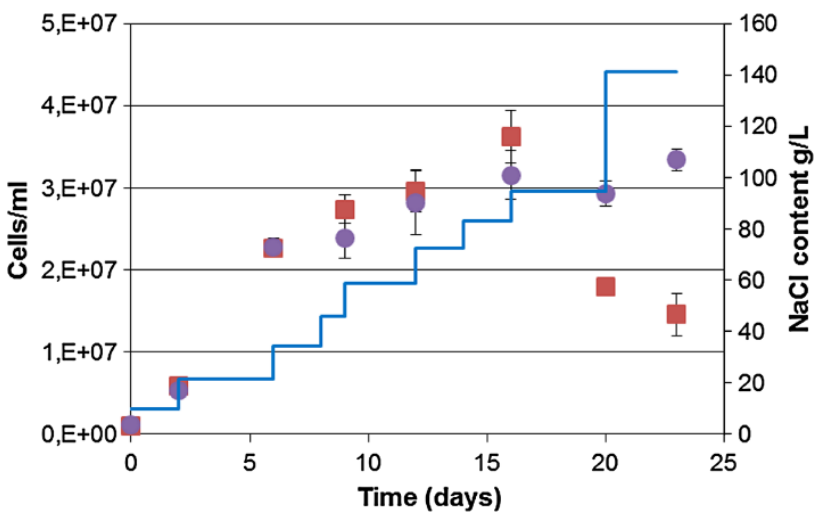

Fig. 3 Growth of C. aponinum $P B 1$ in WM with increasing $\mathrm{NaCl}$ content (filled squares; $\mathrm{NaCl}$ content as line) over time. As control a C. aponinum $\mathrm{PB} 1$ culture growing in WM with $10 \mathrm{~g} \mathrm{~L}^{-1} \mathrm{NaCl}$ is shown (filled circles). Error bars represent three times the standard deviation

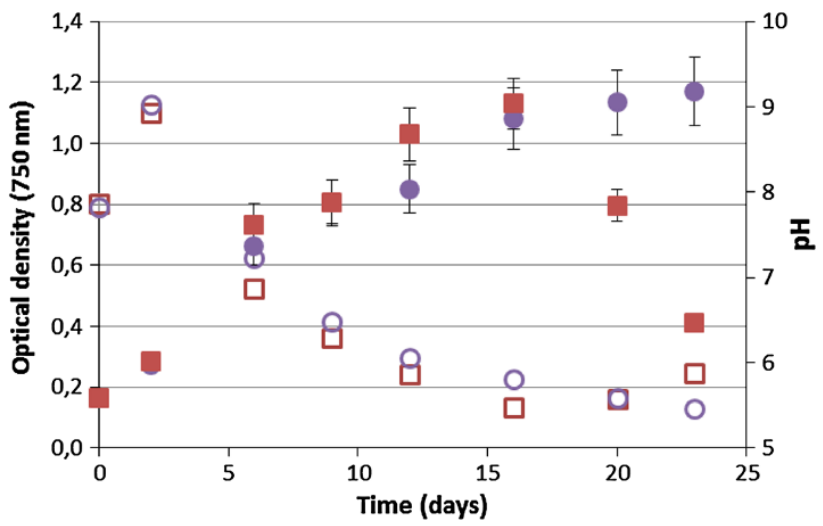

Fig. $4 \mathrm{pH}$ change and growth as measured by optical density of $C$. aponinum $P B 1$ with increasing $\mathrm{NaCl}$ content (pH: open squares; $\mathrm{OD}$ : filled squares) over time. As control a $C$. aponinum $\mathrm{PB} 1$ culture growing in WM with $10 \mathrm{~g} \mathrm{~L}^{-1} \mathrm{NaCl}$ is shown (pH: open circles; OD: filled circles). Error bars represent three times the standard deviation

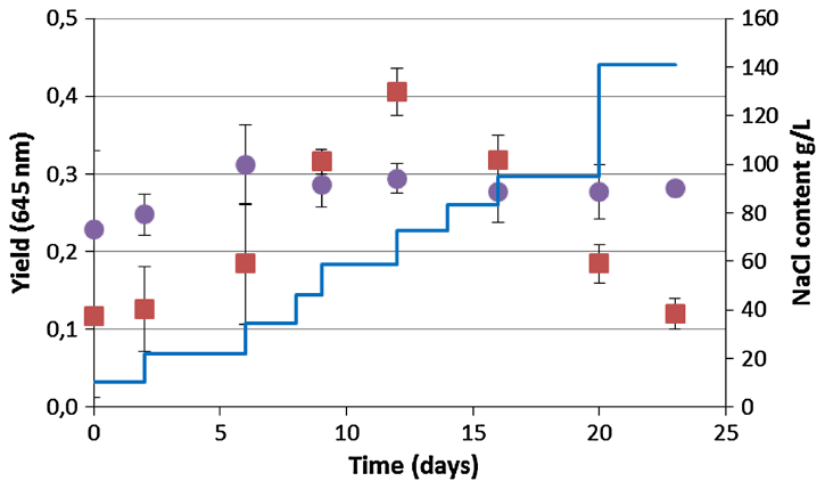

Fig. 5 Photosynthetic yield of $C$. aponinum $P B 1$ with increasing $\mathrm{NaCl}$ content (filled squares; $\mathrm{NaCl}$ content as line) over time. As control a C. aponinum PB1 culture growing in WM with $10 \mathrm{~g} \mathrm{~L}^{-1}$ $\mathrm{NaCl}$ is shown (filled circles). Error bars represent three times the standard deviation 


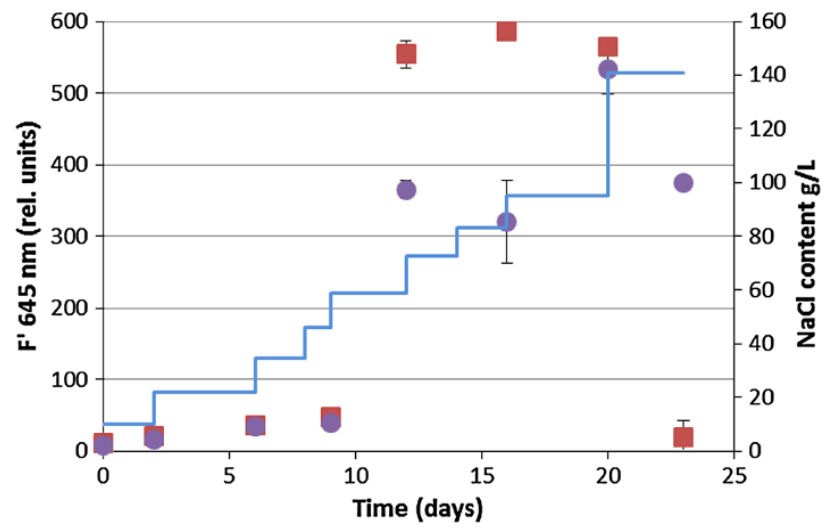

Fig. 6 Change of light-adapted steady state fluorescence $\left(F^{\prime}\right)$ of $C$. aponinum $P B 1$ with increasing $\mathrm{NaCl}$ content (filled squares; $\mathrm{NaCl}$ content as line) over time. As control a $C$. aponinum PB1 culture growing in $\mathrm{WM}$ with $10 \mathrm{~g} \mathrm{~L}^{-1} \mathrm{NaCl}$ is shown (filled circles). Error bars represent three times the standard deviation

The light-adapted fluorescence $\left(\mathrm{F}^{\prime}=645 \mathrm{~nm}\right)$ of the treated and the control culture increases from 10 at a $\mathrm{NaCl}$ content of $10 \mathrm{~g} \mathrm{~L}^{-1}$ to 50 rel. units after growth in media containing $35 \mathrm{~g} \mathrm{~L}^{-1} \mathrm{NaCl}$. The fluorescence values increase steeply during the growth in WM with $58 \mathrm{~g} \mathrm{~L}^{-1}$ $\mathrm{NaCl}$ for both cultures, but while it stays stable for the treated culture till the $\mathrm{NaCl}$ content was increased to $140 \mathrm{~g} \mathrm{~L}^{-1} \mathrm{NaCl}$, after which the fluorescence values drop to undetectable values, it decreases for the control culture on day 16, increases till day 20 and declines till day 23 (Fig. 6).

The relative, normalized fluorescence values of the control culture stayed stable from day 6 to 16 , after which the $\mathrm{NaCl}$ concentration was increased to $92 \mathrm{~g} \mathrm{~L}^{-1}$. Thereafter, RelF $520 \mathrm{~nm}$ and RelF $665 \mathrm{~nm}$ increased slightly. The relF $520 \mathrm{~nm}$ of the stressed culture was slightly higher than the control value and decreased after the $\mathrm{NaCl}$ content was increased to $58 \mathrm{~g} \mathrm{~L}^{-1}$. RelF $665 \mathrm{~nm}$ of the stressed culture showed similar values like the control culture declined after day 10 .

\section{Discussion}

The isolate was assigned to be $C$. aponinum because of the molecular similarities, similar shape and color, and the ability to survive in BG11 media containing $34 \mathrm{~g} \mathrm{~L}^{-1}$ salt. All those features are used to distinguish $C$. aponinum ETS-03 from other Cyanobacteria and to establish the $C$. aponinum species (Moro et al. 2007). Our isolate was found in microbial mats in a warm water pond and able to be free living like C. aponinum ETS-03 (Moro et al. 2007). C. aponinum PB1 showed a change in color during temperature shift or nutrient stress (data not shown) and Moro reported unknown carotenoids in the $C$. aponinum ETS-03.
C. aponinum was found to accumulate up to $45 \%$ lipids per dry weight (Karatay and Dönmez 2011). Because of the ability to most likely survive the temperature conditions to be found at the test field area and the prospect of possible products made us chose $C$. aponinum PB1 for further tests in the laboratory.

Cyanobacterium aponinum PB1 showed no difference in growth until day 8 when the $\mathrm{NaCl}$ content was increased to $92 \mathrm{~g} \mathrm{~L}^{-1}$. The control had reached the stationary phase at that time, while the other culture declined in OD and in cell concentration. C. aponinum PB1 could be part of the functional group of moderately halotolerant cyanobacteria, as defined by Reed and Stewart ((Reed and Stewart 1985). This group is able to synthesize Glucosylglycerol [O-a-Dglucopyranosyl-(1->2)-glycerol] as their major compatible solute as response to increasing salt concentrations. Members of this group were found in sea and fresh water and were able to survive in media containing salt concentrations of double the amount of salt in sea water and even more (Reed and Stewart 1985). Hagemann defined the $\mathrm{NaCl}$ tolerance limit of moderately halotolerant strains as 1.7 M, which coincides with our own findings $(1.7 \mathrm{M} \mathrm{NaCl}$ $\sim 99 \mathrm{~g} \mathrm{~L}^{-1}$ ).

It was shown that cyanobacteria alkalize the growth media when not provided with inorganic carbon (IC) (Kaplan et al. 1989). Cyanobacteria store $\mathrm{CO}_{2}$ in form of IC in carboxysomes (Reinhold et al. 1991). The initial increase of $\mathrm{pH}$ during this experiment indicates an insufficient internal IC pool. This pool is filled over time by the $\mathrm{CO}_{2}$-concentrating mechanism (Kupriyanova et al. 2013) using the excess $\mathrm{CO}_{2}$ from the air leading to a decrease in pH. C. aponinum $\mathrm{PB} 1$ alkalized the medium to $\mathrm{pH}$ values of up to 10.5 during experiments using an insufficient aeration rate (data not shown). Cyanobacteria are able to survive salt stress by a number of different physiological changes. The decrease of $\mathrm{pH}$ until day 20 of the culture grown in $\mathrm{WM}$ with increasing $\mathrm{NaCl}$ compared to the control culture could be because of an increase in $\mathrm{Na}^{+} / \mathrm{H}^{+}$antiporter synthesis during growth in elevated salt levels (Allakhverdiev et al. 1999). It was shown that the artificial induction of a $\mathrm{Na}^{+} / \mathrm{H}^{+}$-antiporter overexpression enabled a freshwater cyanobacterium to survive and grow in seawater (Waditee et al. 2002). Another response to increased salt levels is an increase in unsaturation of membrane lipids leads to a change in plasma membrane mobility (Allakhverdiev et al. 2000a). This might depress the functionality of $\mathrm{K}^{+}$channels, which are also point of entry for $\mathrm{Na}^{+}$ molecules and of water channels (Allakhverdiev et al. $2000 \mathrm{~b}$ ). While in the same moment the synthesis of membrane bound $\mathrm{Na}^{+} / \mathrm{H}^{+}$-antiporter and $\mathrm{H}^{+}$ATPaseenzymes might be increased (Allakhverdiev et al. 2001). All those processes are thought to decrease the $\mathrm{Na}^{+}$content in the cytosol and thereby protecting the photosystems 
against salt-induced inactivation (Singh et al. 2002). The counteracting mechanisms of increased number of enzymes and depression of functionality limit the survival under stress to a certain threshold, which is thought to be reached by the culture growing in increasing salt levels on day 20 , like it is shown in change in $\mathrm{pH}$, growth rate and photosynthetic activity. The mechanisms of lipid unsaturation and solute biosynthesis are said to be not only responsible for salt tolerance but also for tolerance to osmotic or high and low temperatures (Klähn and Hagemann 2011; Singh et al. 2002). Modern proteomic analyses try to explain the mechanisms of heat shock and saltinduced stress in more detail (Castielli et al. 2009; Ludwig 2012).

The photosynthetic yield $645 \mathrm{~nm}$ was below the maximum yield of the stock cultures grown at room temperature. The cultures photosynthetic capability was limited over the whole course of the experiment. The highest yield $645 \mathrm{~nm}$ was measured after growth in media with $58 \mathrm{~g} \mathrm{~L}^{-1}$ with 0.4. At the same day, the OD was significantly higher compared to the control culture. Afterwards, the yield decreased steadily and a decrease in growth could not be seen before a decrease in cell concentration or OD was measurable. Also the other fluorescence parameters were not reliable to indicate $\mathrm{NaCl}$ stress. Under controlled laboratory conditions, fluorescence values of dark-adapted and biomass-standardized samples were found to be reliable indicators for various stressors (Lu and Vonshak 1999). But the use of fluorescence values under less controlled conditions was found to be not reliable (Kruskopf and Flynn 2006).

The utilization of $\mathrm{pH}$ measurements as control parameter for culture stability could be used to indicate $\mathrm{CO}_{2}$ depletion. A different method or changes in the measurement procedure have to be found to use PAM as control parameter for culture stability. A bypass with rest time for dark adaption might be an answer for semi-continuous online measurement.

The possible growth in temperatures above $30{ }^{\circ} \mathrm{C}$ in easy-made liquid media in combination with its free-living growth form predestine $C$. aponinum PB1 for field tests in the Omanian desert.

The mean conductivity of the feed water was measured with $14 \mathrm{~ms} \mathrm{~cm}^{-1}$ (personal communication). The maximum natural evaporation on the Arabic peninsula is difficult to measure and values of up to $14 \mathrm{~mm}$ per day are reported (Alsharhan et al. 2001). Evaporation would be even higher because of the by circulation enlarged surface of the algae culture. We assumed a maximum evaporation of $20 \mathrm{~mm}$ per day. The theoretical maximal conductivity, while harvesting every third day, due to evaporation would be $24 \mathrm{~ms} \mathrm{~cm}^{-1}$, which correlates to the conductivity of a $\mathrm{NaCl}$ solution with $14 \mathrm{~g} \mathrm{~L}^{-1}$ (Lewis 1980). Therefore, as long as the main salt in the feed water is $\mathrm{NaCl}$ (Nübel et al. 2000) C. aponinum PB1 should be able to grow. The salt in the feed water might have a positive impact on the lipid content because higher salt levels were shown to increase lipid accumulation in cyanobacteria (Araujo et al. 2011; Bhadauriya et al. 2008).

Assuming a theoretical exponential growth with an average growth rate of $0.3 \mu$ per day in a $10 \mathrm{~cm}$ deep open pond a biomass yield of $22,500 \mathrm{~kg}$ per hectare and year (expecting 300 working days) could be achieved. With a caloric value of $20 \mathrm{~kJ}$ per $10 \mathrm{~g}$ dry weight, like it was published for other cyanobacteria (Quintana et al. 2011), this would correspond to an energy content of $50,000 \mathrm{Mj}$. Similar and higher growth rates were reported for other cyanobacteria (Markou and Georgakakis 2011). A possible lipid yield of up to $10,125 \mathrm{~kg}$ of lipids per hectare and year if $45 \%$ lipids per dry weight might be achieved (Karatay and Dönmez 2011). The usability as biodiesel highly depends on the lipid composition (Quintana et al. 2011), which is influenced by the growth stage, growth temperature and light intensity (Liu et al. 2005; Vargas et al. 1998; Walsh et al. 1997).

Presume exponential growth at dry weight concentrations below $0.37 \mathrm{~g} \mathrm{~L}^{-1}$ and harvesting two-third of the whole volume every three days $65,000 \mathrm{~m}^{3}$ have to be moved per year. Assuming an average evaporation rate of $14 \mathrm{~mm}$ per day additional $140,000 \mathrm{~m}^{3}$ of water have to be pumped. This accumulates to an energy consumption of 20,000 Mj for liquid movement alone.

To be able to give a final statement about the economic feasibility of an algae production process using $C$. aponinum the actual biomass composition achievable in large scale and possible synergies with established procedures have to be evaluated (Patel et al. 2012).

Acknowledgments We would like to thank Gerhard Kauer (Univeristy of Applied Sciences Emden) for his help. The project underlying this report was funded by the Federal Ministry of Education and Research of Germany under grant number FHprofUnt $17003 X 11$ promoted. The responsibility for the content of this publication lies with the author.

Open Access This article is distributed under the terms of the Creative Commons Attribution License which permits any use, distribution, and reproduction in any medium, provided the original author(s) and the source are credited.

\section{References}

Allakhverdiev SI, Nishiyama Y, Suzuki I, Tasaka Y, Murata N (1999) Genetic engineering of the unsaturation of fatty acids in membrane lipids alters the tolerance of Synechocystis to salt stress. Proc Natl Acad Sci U S A 96(10):5862-5867. Retrieved from http://www.pubmedcentral.nih.gov/articlerender.fcgi? artid $=21951 \&$ tool $=$ pmcentrez $\&$ rendertype $=$ abstract 
Allakhverdiev SI, Sakamoto A, Nishiyama Y, Inaba M, Murata N (2000a) Ionic and osmotic effects of $\mathrm{NaCl}$-induced inactivation of photosystems I and II in Synechococcus sp. Plant Physiol 123(3):1047-1056. Retrieved from http://www.pubmedcentral. nih.gov/articlerender.fcgi?artid=59068\&tool=pmcentrez\&render type=abstract

Allakhverdiev SI, Sakamoto A, Nishiyama Y, Murata N (2000b) Inactivation of photosystems I and II in response to osmotic stress in Synechococcus. Contribution of water channels. Plant Physiol 122(4):1201-1208. Retrieved from http://www. pubmedcentral.nih.gov/articlerender.fcgi?artid=58955\&tool $=\mathrm{pm}$ centrez\&rendertype $=$ abstract

Allakhverdiev SI, Kinoshita M, Inaba M, Suzuki I, Murata N (2001) Unsaturated fatty acids in membrane lipids protect the photosynthetic machinery against salt-induced damage in Synechococcus. Plant Physiol 125(4):1842-53. Retrieved from http:// www.pubmedcentral.nih.gov/articlerender.fcgi?artid=88840\&tool $=$ pmcentrez\&rendertype $=$ abstract

Alsharhan AS, Rizk ZA, Nairn AEM, Bakhit DW, Alhajari SA (2001) Physical geography of the Arabian Peninsula. In: AS Alsharhan, ZA Rizk, AEM Nairn, DW Bakhit, SA Alhajari (eds.) Hydrogeology of an arid region: the arabian gulf and adjoining areas, Elsevier Science BV, Amsterdam, pp. 7-53 doi:http://dx.doi.org/ 10.1016/B978-044450225-4/50003-8

Altschup SF, Gish W, Miller W, Myers EW, Lipman DJ (1990) Basic local alignment search tool. J Mol Biol 215:403-410

Araujo GS, Matos LJBL, Gonçalves LRB, Fernandes FAN, Farias WRL (2011) Bioprospecting for oil producing microalgal strains: evaluation of oil and biomass production for ten microalgal strains. BioResour Technol 102(8):5248-5250. doi:10.1016/j.biortech.2011.01.089

Behrenfeld MJ, Prasil O, Babin M, Bruyant F (2004) In search of a physiological basis for covariations in light-limited and lightsaturated photosynthesis 1. J Phycol 40(1):4-25. doi:10.1046/j. 1529-8817.2004.03083.x

Bhadauriya P, Gupta R, Singh S, Bisen PS (2008) NaCl induced metabolic changes in the diazotrophic cyanobacterium Anabaena cylindrica. World J Microbiol Biotechnol 25(2):341-345. doi:10. 1007/s11274-008-9879-z

Boutte C, Grubisic S, Balthasart P, Wilmotte A (2006) Testing of primers for the study of cyanobacterial molecular diversity by DGGE. J Microbiol Method 65(3):542-550. doi:10.1016/j. mimet.2005.09.017

Breuer R, Al-Asmi S (2010) NIMR water treatment project-up scaling a reed bed trail to industrial. In: SPE international conference on health, safety and environment in oil and gas exploration and production, vol 1. pp 286-296

Campbell D, Hurry V, Clarke AK, Gustafsson P, Öquist G (1998) Chlorophyll fluorescence analysis of cyanobacterial photosynthesis and acclimation chlorophyll fluorescence analysis of cyanobacterial photosynthesis and acclimation. Microbiol Mol Biol Rev 62(3):667-683

Castielli O, De la Cerda B, Navarro JA, Hervás M, De la Rosa MA (2009) Proteomic analyses of the response of cyanobacteria to different stress conditions. FEBS Lett 583(11):1753-1758. doi:10.1016/j.febslet.2009.03.069

Chisti Y (2008) Biodiesel from microalgae beats bioethanol. Trends Biotechnol 26(3):126-131. doi:10.1016/j.tibtech.2007.12.002

Chisti Y (2013) Constraints to commercialization of algal fuels. J Biotechnol 167(3):201-214. doi:10.1016/j.jbiotec.2013.07.020

Grobbelaar JU (2000) Physiological and technological considerations for optimising mass algal cultures. J Appl Phycol 12:201-206

Grobbelaar JU (2009) Upper limits of photosynthetic productivity and problems of scaling. J Appl Phycol 21(5):519-522. doi:10.1007/ s10811-008-9372-y
Grobbelaar JU (2012) Microalgae mass culture: the constraints of scaling-up. J Appl Phycol 24(3):315-318. doi:10.1007/s10811011-9728-6

Guieysse B, Béchet Q, Shilton A (2013) Variability and uncertainty in water demand and water footprint assessments of fresh algae cultivation based on case studies from five climatic regions. Bioresour Technol 128:317-323. doi:10.1016/j.biortech.2012. 10.096

Havlik I, Lindner P, Scheper T, Reardon KF (2013) On-line monitoring of large cultivations of microalgae and cyanobacteria. Trends Biotechnol 31(7):406-414. doi:10.1016/j.tibtech. 2013.04.005

Janse I, Meima M, Kardinaal WEA, Zwart G (2003) High-resolution differentiation of cyanobacteria by using rRNA-internal transcribed spacer denaturing gradient gel electrophoresis highresolution differentiation of cyanobacteria by using rRNAinternal transcribed spacer denaturing gradient gel electroph. Appl Environ Microbiol 69(11):6634-6643. doi:10.1128/AEM. 69.11 .6634

Kaplan A, Scherer S, Lemer M (1989) Nature of the light-induced $\mathrm{H}+$ Efflux and $\mathrm{Na}+$ Uptake in, 1220-1225

Karatay SE, Dönmez G (2011) Microbial oil production from thermophile cyanobacteria for biodiesel production. Appl Energy 88(11):3632-3635. doi:10.1016/j.apenergy.2011.04.010

Klähn S, Hagemann M (2011) Compatible solute biosynthesis in cyanobacteria. Environ Microbiol 13(3):551-562. doi:10.1111/j. 1462-2920.2010.02366.x

Kolbowski J, Schreiber U (1995) Computer-controlled phyto- plankton analyzer based on a 4-wavelength PAM Chl fluoro meter. In: Mathis P (ed) Photosynthesis: from light to biosphere. Kluwer Academic Publishers, Dordrecht, Boston, London

Kruskopf M, Flynn KJ (2006) Chlorophyll content and fluorescence responses cannot be used to gauge reliably phytoplankton biomass, nutrient status or growth rate. New Phytol 169:525-536. doi:10.1111/j.1469-8137.2005.01601.x

Kupriyanova EV, Sinetova MA, Cho SM, Park Y-I, Los DA, Pronina NA (2013) CO2-concentrating mechanism in cyanobacterial photosynthesis: organization, physiological role, and evolutionary origin. Photosynth Res 117(1-3):133-146. doi:10.1007/ s11120-013-9860-z

Lewis E (1980) The practical salinity scale 1978 and its antecedents. IEEE J Ocean Eng 5. doi:10.1109/JOE.1980.1145448

Liu X-J, Jiang Y, Chen F (2005) Fatty acid profile of the edible filamentous cyanobacterium Nostoc flagelliforme at different temperatures and developmental stages in liquid suspension culture. Process Biochem 40(1):371-377. doi:10.1016/j.procbio. 2004.01.018

Lu C, Vonshak A (1999) Characterization of PSII photochemistry in salt-adapted cells of cyanobacterium Spirulina platensis. New Phytol 141:231-239

Ludwig M, Bryant DA (2012) Synechococcus sp. strain PCC 7002 transcriptome: acclimation to temperature, salinity, oxidative stress, and mixotrophic growth conditions. Front Microbiol 3:354. doi:10.3389/fmicb.2012.00354

Markou G, Georgakakis D (2011) Cultivation of filamentous cyanobacteria (blue-green algae) in agro-industrial wastes and wastewaters: a review. Appl Energy 88:3389-3401. doi:10.1016/j. apenergy.2010.12.042

Moro I, Rascio N, Di Bella M, Andreoli C, La Rocca N (2007) Cyanobacterium aponinum, a new Cyanoprokaryote from the microbial mat of Euganean thermal springs (Padua, Italy). Arch Hydrobiol Suppl Algol Stud. doi:10.1127/1864-1318/2007/01230001

Mutanda T, Ramesh D, Karthikeyan S, Kumari S, Anandraj A, Bux F (2011) Bioprospecting for hyper-lipid producing microalgal 
strains for sustainable biofuel production. BioResour Technol 102(1):57-70. doi:10.1016/j.biortech.2010.06.077

Nedelcu AM (2006) Evidence for p53-like-mediated stress responses in green algae. FEBS Lett 580(13):3013-3017. doi:10.1016/j. febslet.2006.04.044

Nübel U, Garcia-Pichel F, Clavero E, Muyzer G (2000) Matching molecular diversity and ecophysiology of benthic cyanobacteria and diatoms in communities along a salinity gradient. Environ Microbiol 2(2):217-226. Retrieved from http://www.ncbi.nlm. nih.gov/pubmed/11220307

Odlare M, Nehrenheim E, Ribé V, Thorin E, Gavare M, Grube M (2011) Cultivation of algae with indigenous species-potentials for regional biofuel production. Appl Energy 88(10):3280-3285. doi:10.1016/j.apenergy.2011.01.006

Patel B, Tamburic B, Zemichael FW, Dechatiwongse P, Hellgardt K (2012) Algal biofuels: a credible prospective? ISRN Renew Energy. doi:10.5402/2012/631574

Quintana N, Van der Kooy F, Van de Rhee MD, Voshol GP, Verpoorte R (2011) Renewable energy from Cyanobacteria: energy production optimization by metabolic pathway engineering. Appl Microbiol Biotechnol 91(3):471-490. doi:10.1007/ s00253-011-3394-0

Reed RH, Stewart WDP (1985) Osmotic adjustment and organic solute accumulation in unicellular cyanobacteria from freshwater and marine habitats. Mar Biol 88:1-9

Reinhold L, Kosloff R, Kaplan A (1991) A model for inorganic carbon fluxes and photosynthesis in cyanobacterial carboxysomes. Can J Bot. doi:10.1139/b91-126

Schreiber U, Schliwa U, Bilger W (1986) Continuos recording of photochemical and non-photochemical chlorophyll fluorescence quenching with a new type of modulation fluorometer. Photosynth Res 10:51-62
Schreiber U, Endo T, Mi H, Asada K (1995) Quenching analysis of chlorophyll fluorescence by the saturation pulse method: particular aspects relating to the study of eukaryotic algae and cyanobacteria. Plant Cell 36(5):873-882

Singh SC, Sinha RP, Häder D (2002) Role of lipids and fatty acids in stress tolerance in cyanobacteria. Acta Protozool 41:297-308

Singh A, Nigam PS, Murphy JD (2011) Renewable fuels from algae: an answer to debatable land based fuels. BioResour Technol 102(1):10-16. doi:http://dx.doi.org/10.1016/j.biortech.2010.06.032

Van Beilen JB (2010) Why microalgal biofuels won't save the internal combustion. Biofuels Bioprod Biorefining 4:41-52. doi: $10.1002 / b b b$

Vargas MA, Rodríguez H, Moreno J, Olivares H, Del Campo JA, Rivas, JGuerrero MG (1998) Biochemical composition and fatty acid content of filamentous nitrogen-fixing cyanobacteria. J Phycol 817:812-817

Waditee R, Hibino T, Nakamura T, Incharoensakdi A, Takabe T (2002) Overexpression of a $\mathrm{Na}+/ \mathrm{H}+$ antiporter confers salt tolerance on a freshwater cyanobacterium, making it capable of growth in sea water. Proc Natl Acad Sci USA 99(6):4109-4114. doi:10.1073/pnas.052576899

Walsh K, Jones GJ, Dunstan RH (1997) Effect of irradiance on fatty acid, carotenoid, total protein composition and growth of Microcystis aeruginosa. Phytochemistry 44(5):817-824

Watanabe MM (2005) Freshwater culture media. In: A Anderson, Robert A (ed.) Algal culturing techniques. Elsevier Academic Press, Amsterdam, Boston, Heidelberg, London, New York, Oxford, Paris, San Diego, San Francisco, Singapore, Sydney, Tokyo, pp. 13-20 